\title{
A common functional variant on the pro-inflammatory Interleukin-6 gene may modify the association between long-term $\mathrm{PM}_{10}$ exposure and diabetes
}

Ikenna C. Eze ${ }^{1,2}$, Medea Imboden ${ }^{1,2}$, Ashish Kumar ${ }^{1,2,3}$, Martin Adam ${ }^{1,2}$, Arnold von Eckardstein ${ }^{4}$, Daiana Stolz ${ }^{5}$, Margaret W. Gerbase ${ }^{6}$, Nino Künzli ${ }^{1,2}$, Alexander Turk ${ }^{7}$, Christian Schindler ${ }^{1,2}$, Florian Kronenberg ${ }^{8,9}$

and Nicole Probst-Hensch ${ }^{1,2^{*}}$

\begin{abstract}
Background: Air pollutants have been linked to type 2 diabetes (T2D), hypothesized to act through inflammatory pathways and may induce interleukin-6 gene (IL6) in the airway epithelium. The cytokine interleukin-6 may impact on glucose homeostasis. Recent meta-analyses showed the common polymorphisms, IL6-572G >C and IL6-174G >C to be associated with T2D risk. These $I L 6$ variants also influence circulatory interleukin-6 levels. We hypothesize that these common functional variants may modify the association between air pollutants and T2D.

Methods: We cross-sectionally studied 4410 first follow-up participants of the Swiss Cohort Study on Air Pollution and Lung and Heart Diseases (SAPALDIA), aged 29 to 73 years who had complete data on genotypes, diabetes status and covariates. We defined diabetes as self-reported physician-diagnosed, or use of diabetes medication or non-fasting glucose $>11.1 \mathrm{mmol} / \mathrm{L}$ or $\mathrm{HbA} 1 \mathrm{c}>0.065$. Air pollution exposure was 10-year mean particulate matter $<10 \mu \mathrm{m}$ in diameter $\left(\mathrm{PM}_{10}\right)$ assigned to participants' residences using a combination of dispersion modelling, annual trends at monitoring stations and residential history. We derived interaction terms between $\mathrm{PM}_{10}$ and genotypes, and applied mixed logistic models to explore genetic interactions by $I L 6$ polymorphisms on the odds of diabetes.

Results: There were 252 diabetes cases. Respective minor allele frequencies of $I L 6-572 G>C$ and IL6 -174G >C were 7 and $39 \%$. Mean exposure to $\mathrm{PM}_{10}$ was $22 \mathrm{\mu g} / \mathrm{m}^{3}$. Both variants were not associated with diabetes in our study. We observed a significant positive association between $\mathrm{PM}_{10}$ and diabetes among homozygous carriers of the pro-inflammatory major G-allele of IL6 -572G > C [Odds ratio: 1.53; $95 \%$ confidence interval $(1.22,1.92) ; P_{\text {interaction (additive) }}=0.003$ and $\left.P_{\text {interaction (recessive) }}=0.006\right]$. Carriers of the major $G$-allele of $I L 6-174 G>C$ also had significantly increased odds of diabetes, but interactions were statistically non-significant.

Conclusions: Our results on the interaction of $\mathrm{PM}_{10}$ with functionally well described polymorphisms in an important pro-inflammatory candidate gene are consistent with the hypothesis that air pollutants impact on T2D through inflammatory pathways. Our findings, if confirmed, are of high public health relevance considering the ubiquity of the major $\mathrm{G}$ allele, which puts a substantial proportion of the population at risk for the development of diabetes as a result of long-term exposure to air pollution.
\end{abstract}

Keywords: Particulate matter, Air pollution, Diabetes mellitus, Interleukin-6 gene, Gene-environment interactions, Single nucleotide polymorphisms, Cross-sectional epidemiology

\footnotetext{
*Correspondence: nicole.probst@unibas.ch

${ }^{1}$ Swiss Tropical and Public Health Institute, Basel, Switzerland

2University of Basel, Basel, Switzerland

Full list of author information is available at the end of the article
} 


\section{Background}

Evidence suggests a positive association between ambient air pollution and risk of type 2 diabetes (T2D) [1-3]. This association is hypothesized to be mediated through inflammatory mechanisms. Experimental evidence $[4,5]$ suggests subclinical systemic inflammation occurring at several sites including adipose tissue, liver, skeletal muscles and the autonomic nervous system, with resultant insulin resistance, the hallmark of T2D. On the population level, acute and long-term exposure to ambient air pollution has been linked to raised markers of inflammation including circulating C-reactive proteins (CRP) $[6,7]$ IL-6, [8] fibrinogen $[9,10]$ vascular and intracellular adhesion molecules [11]. Indeed, air pollution is thought to accelerate pro-thrombotic state following lung inflammation through an IL-6 dependent pathway $[12,13]$. Exposure to industrial particulate matter has been shown to induce IL6 genes in human airway epithelial cells [14]. Likewise, exposure of mice to particulate matter induced the expression of genes involved in inflammation, lipid metabolism and atherosclerosis [8].

IL-6 in itself may be related to the development of type 2 diabetes [15]. Elevated levels of IL-6 were associated with higher incidence of type 2 diabetes [16, 17], and animal studies also showed IL-6 to inhibit insulin secretion from islet cells following glucose stimulation [18]. Other in vitro studies also showed negative impacts of IL-6 on insulin sensitivity through reduced insulin receptor expression [19] and adiponectin gene expression [20] in adipocytes. Among T2D patients, IL-6 was associated with whole-body insulin resistance and hyperglycemia [21]. Raised IL-6 levels were also associated with hyperinsulinemia in patients without T2D [22].

IL6 gene plays an important role in the regulation of systemic inflammatory pathways. Some common single nucleotide polymorphisms (SNPs), including IL6 -572G > C and IL6 -174G > C have been shown to influence the levels of circulatory IL-6 [23, 24], as well as circulating CRP [25]. In these studies, the major $\mathrm{G}$ alleles of both variants were identified as the pro-inflammatory alleles. Recent metaanalyses of 11,681 individuals of Asian and European descent showed the G allele of IL6 -572G > C to be associated with increased risk of T2D [26] whereas another study of 22,626 individuals of European descent showed the $C$ allele of IL6 $-174 \mathrm{G}>\mathrm{C}$ to be associated with decreased risk of T2D [27].

Studying gene-environment interactions helps to better understand aetiologic mechanisms and causality of exogenous factors, in this case, air pollution, and to identify population at increased risk of adverse health effects of environmental exposures. We hypothesize, based on the above evidence, that the common functional SNPs, IL6 -572G > C and IL6 -174G > C, may modify the existing association between air pollutants and diabetes [28].

\section{Methods}

\section{Study population}

We studied participants of the Swiss Cohort Study on Air Pollution and Lung and Heart Diseases in Adults (SAPALDIA). This study has been described elsewhere in detail [29]. Briefly, it consists of a population-based sample of 9651 adults, aged 18-60 when they were recruited at baseline (1990/1991) from eight communities reflecting the diverse geographic and climatic features of Switzerland. Participants underwent health interviews and physical examinations. At first follow-up (2001/2002) which additionally included blood marker and genetic assays, 8047 participants completed at least the screening questionnaire [30]. 6212 participants at first follow-up, consenting to genetic assays were genotyped for IL6 -572G > C and IL6 -174G > C in those studies. For the present analysis, we studied 4410 follow-up participants, aged 29-73 years, with complete data on diabetes status, selected covariates, and population stratification data from genome-wide association studies. The algorithm for participant selection is shown on Fig. 1.

Participants provided informed consent for participation in the health interviews, physical examinations, blood marker and genetic assays. Ethical clearance for the SAPALDIA study was obtained from the Swiss Academy of Medical Sciences, the National Ethics Committee for Clinical research (UREK, Project Approval Number 123/00) and the Ethics Committees of the eight participating communities including Basel, Wald, Davos, Lugano, Montana, Payerne, Aarau and Geneva.

\section{Identification of diabetes cases}

Participants were identified as having diabetes if they 1) reported physician diagnosed diabetes or 2) use of diabetes medication in the past month or 3) had nonfasting blood glucose $>11.1 \mathrm{mmol} / \mathrm{L}$ or 4$) \mathrm{HbA} 1 \mathrm{c}>0.065$. Non-fasting blood glucose was measured in all participants whereas HbAlc was only measured if non-fasting glucose $>6.1 \mathrm{mmol} / \mathrm{L}$ [28]. The lack of data on diabetes status at baseline precluded the study of incident diabetes. Also, we could not exclude type 1 diabetes (T1D) and have assumed the majority of these cases to be T2D considering that on the average, $>90 \%$ of adult diabetes are T2D [31].

\section{Individual assignment of air pollution exposure}

We considered 10-year means of $\mathrm{PM}_{10}$ (particulate matter $<10$ um in diameter) as our pollutant exposure measure of interest. In our previous studies on diabetes [2] and metabolic syndrome [32], associations with nitrogen dioxide $\left(\mathrm{NO}_{2}\right)$ disappeared in two-pollutant models that included $\mathrm{NO}_{2}$ and $\mathrm{PM}_{10}$, whereas those of $\mathrm{PM}_{10}$ remained unchanged. Therefore we did not consider $\mathrm{NO}_{2}$ in this study. Estimates of $\mathrm{PM}_{10}$ exposure were 


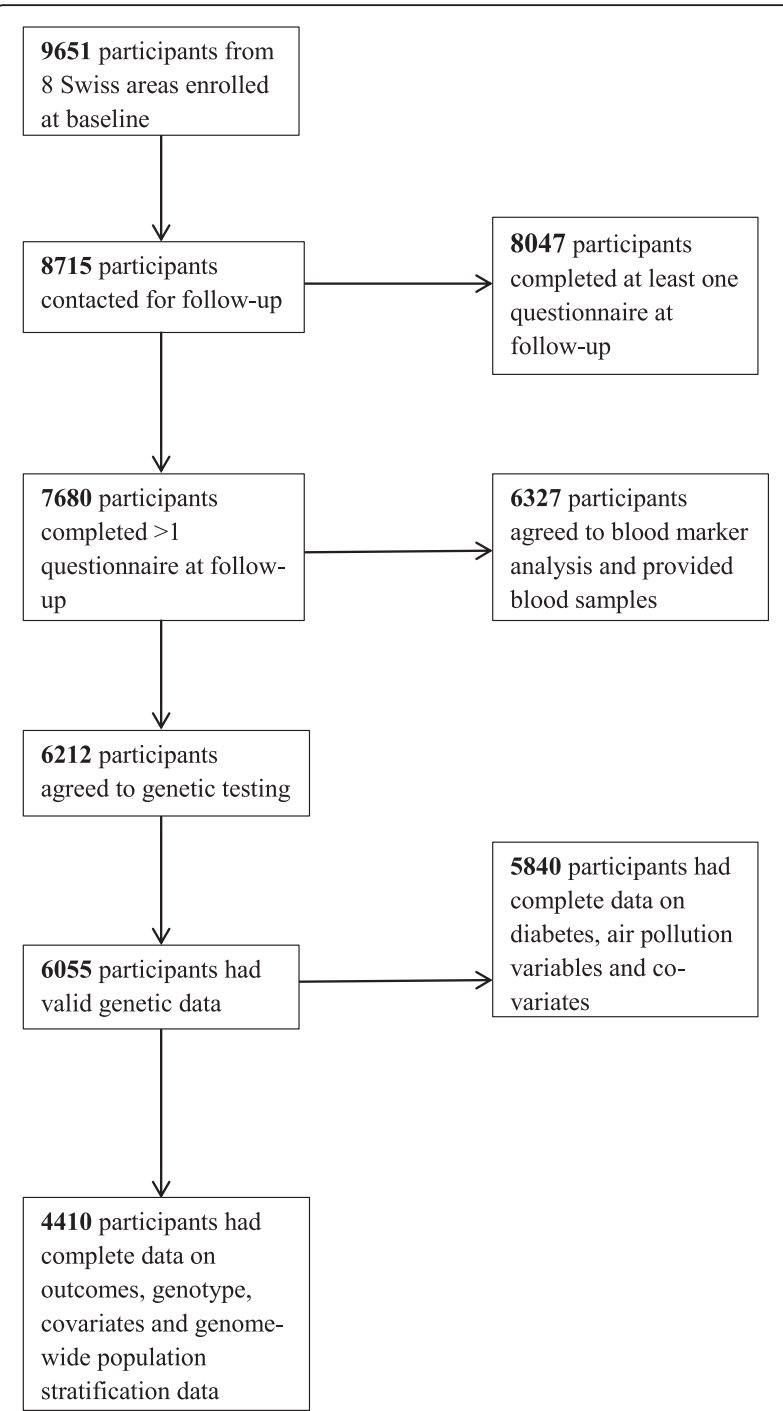

Fig. 1 Algorithm for participant inclusion in the present study

assigned to participants' residential addresses using dispersion models for the years 1990 and 2000 (respective years before baseline and follow-up) [33]. This model incorporated data from meteorology, topography and several emission inventories including industrial, agricultural, heavy equipment and traffic at a resolution of $200 \times 200 \mathrm{~m}$ [34]. Annual $\mathrm{PM}_{10}$ levels measured at fixed monitoring stations across Switzerland and participants' residential histories were further used to derive estimates of mean $\mathrm{PM}_{10}$ exposure at participants' residential addresses over the 10-year period preceding the first follow-up health examination [28].

Genotyping of candidate SNPs, IL6 -572G $>\mathrm{C}$ and IL6 -174G > C.

Genomic DNA was extracted from ethylenediaminetetraacetic acid (EDTA)-buffered whole blood using PUREGENE DNA Purification Kit (GENTRA Systems,
Minneapolis, USA) [30]. Genotyping for these polymorphisms was done using 5'-nuclease fluorescent polymerase chain reaction (Taqman) assay (Applera Europe, Rotkreuz, Switzerland). Detection of end-points was done using a 7000 ABI System detection device (ABI, Rotkreuz, Switzerland) [35]. Genotyping call rate was $>97.5 \%$. A random selection of 638 samples (10\%) was genotyped twice for quality control and repeated genotypes were $100 \%$ concordant $\left(R^{2}=1 ; P<0.001\right)$. Subsamples of 3015 and 1612 SAPALDIA participants had whole genome genotyping using the Illumina HumanOmniExomeExpress BeadChip and Illumina $610 \mathrm{~K}$ quad BeadChip (Illumina, San Diego, CA, USA) respectively. In this combined SAPALDIA subsample which are predominantly of Caucasian ancestry, we derived ten population stratification components using multidimensional scaling analysis (Plink v1.07 [36]) on 72,122 SNPs with MAF $>1 \%$ and genotyping call rate $>97 \%$, present on both genotyping arrays.

\section{Potential confounders}

We considered the following characteristics, based on our previous publication on air pollution and diabetes [28], as potential confounders: age (years; continuous), sex, years of formal education $(\leq 9 ;>9)$, neighbourhood socio-economic index developed from a principal component analysis including occupation and educational level of household head, median rent and number of persons living in a household, expressed as a percentage [37]. We also considered smoking history (current, former and never smoker; and smoked pack-years computed by multiplying number of cigarette packs per year and number of smoking years), exposure to passive smoke (yes/no), occupational exposure to vapours gases, dusts and fumes (yes/no) daily consumption of at least one portion of fruits and vegetables (never; $\leq 3$ days/ week; $>3$ days/week respectively). We also considered alcohol consumption (including beers, wines, spirits and liquors: never; $\leq 1$ glass/day; >1glass/day); hours per week of vigorous physical activity defined as taking part in activities that make one sweat or out of breath $(<0.5 ; \geq 0.5)$, body mass index (BMI; $\mathrm{kg} / \mathrm{m}^{2}$, continuous) and genomewide population stratification components.

\section{Statistical analyses}

We assessed linkage disequilibrium between IL6 -572G > C and IL6 -174G > C and tested both candidate SNPs for Hardy-Weinberg equilibrium (HWE) among the genotyped participants regardless of inclusion in the study. We computed an IL6 genetic risk score (IRS) by summing up the risk alleles (number of $\mathrm{G}$ alleles coded as 0,1 and 2) across both SNPs. We summarized the characteristics of 4410 included participants based on their genotype and also by inclusion and exclusion status. We applied a mixed 
logistic regression model, with a random intercept by study area to explore the associations of diabetes with both SNPs, IRS and with $\mathrm{PM}_{10}$. We generated interaction terms between $\mathrm{PM}_{10}$ and candidate SNPs (including IRS) and assessed their associations with prevalent diabetes. Interaction analyses with candidate SNPs involved additive, recessive and co-dominant models. Stratifying by genotype, we assessed the associations between $\mathrm{PM}_{10}$ and diabetes, to identify genotype-specific associations. We also stratified by groups of IRS indicating increased inflammatory risk. Since this study included $46 \%$ of baseline participants which differed in several sociodemographic characteristics (Additional file 1: Table S1), we assessed the effect of potential participant selection bias on our results using inverse probability weighting by applying the inverse of the probability of participating in present study derived at baseline (using variables that significantly predicted participation in the present study), to the primary model in this study. All analyses were performed using a primary model which included, after stepwise selection, participants' age, sex, educational attainment, neighbourhood socio-economic index, smoking status, smoked packyears, exposure to passive smoke, occupational exposure to vapours, gases, dusts and fumes, consumption of fruits and vegetables, vigorous physical activity, BMI and genome-wide population stratification components and applying a random intercept by study area.

We performed several sensitivity analyses. We defined diabetes based on each of the diagnostic criteria (excluding the cases identified only by alternative criteria). We repeated the interaction analyses using mixed logistic regression models with random slopes by study area to explore if study area influenced any of the observed interactions. All statistical analyses were performed with STATA software, version 14 (Stata Corporation, Texas).

\section{Results}

There were 252 diabetes cases in this study. Mean exposure to $\mathrm{PM}_{10}$ was $22.6 \mathrm{ug} / \mathrm{m}^{3}$ and mean IRS was 3 risk alleles. IL6 $-572 \mathrm{G}>\mathrm{C}$ and IL6 $-174 \mathrm{G}>\mathrm{C}$ were not in linkage disequilibrium $\left(R^{2}=0.02 ; D^{\prime}=1.0\right)$. The results of the HWE test for IL6 -572G > C and IL6 -174G > C, which have respective minor allele frequency of 7 and $39 \%$ in the SAPALDIA population are shown in Table 1. IL6 -174G > C was in HWE in both cases and controls whereas IL6 $-572 \mathrm{G}>\mathrm{C}$ only reached HWE among the diabetes cases $(P=0.636)$ and not among those without diabetes $(P=0.006)$. The overall HWE test for IL6 $-174 \mathrm{G}>\mathrm{C}$ and IL6 $-572 \mathrm{G}>\mathrm{C}$ was 0.408 and 0.006 respectively (Table 1). In the European study of $\sim 6000$ participants reporting an association between IL6 -572G > C and T2D, this functional SNP (having MAF $=5 \%$ ) was also not in HWE [38]. Since only 30 participants carry the minor CC genotype of IL6 $-572 \mathrm{G}>\mathrm{C}$, we present the results for
Table 1 Distribution of IL6 -572 G>C and IL6 -174 G>C genotypes and alleles by diabetes status

\begin{tabular}{lll}
\hline Genotype & Diabetes & No diabetes \\
& $N=286$ & $N=5554$ \\
\hline IL6 -572 G>C & \\
Genotype & & \\
GG & $248(86.7)$ & $4896(88.2)$ \\
GC & $36(12.6)$ & $623(11.2)$ \\
CC & $2(0.7)$ & $35(0.6)$ \\
Allele & & $10415(93.7)$ \\
G & $532(93)$ & $693(6.3)$ \\
C & $40(7)$ & \\
IL6 -174 G $>C^{* *}$ & & $2081(37)$ \\
Genotype & & $2614(47)$ \\
GG & $111(39)$ & $865(16)$ \\
GC & $135(47)$ & \\
CC & $40(14)$ & $6776(61)$ \\
Allele & & $4344(39)$ \\
G & $357(62)$ & \\
C & $215(38)$ & \\
\hline
\end{tabular}

Data are presented as absolute numbers (N) and relative numbers (\%) in parentheses

${ }^{*} P$-value for Hardy-Weinberg Equilibrium (HWE) test in diabetes cases $=0.585$; no diabetes $=0.006$; overall $=0.006$. $P$-value for Fisher's exact test $=0.664$

${ }^{* *} P$-value for Hardy-Weinberg Equilibrium test in diabetes cases $=0.918$; no diabetes $=0.352$; overall $=0.408$. $P$-value of Chi-square test $=0.762$

this SNP as GG vs. GC + CC, which yields better statistical power.

Compared to the carriers of the major GG genotype, carriers of the GC+CC genotype of IL6-572G > C had higher body mass index and $\mathrm{PM}_{10}$ exposure whereas carriers of CC genotype of IL6 -174G > C smoked more, consumed more alcohol and had lower exposure to $\mathrm{PM}_{10}$ and there was a significant difference in genotype distribution across areas (Table 2). There was no significant difference in diabetes prevalence across genotypes for both polymorphisms (Table 2). Additional file 1: Table S1 shows the differences in these characteristics between the included and excluded participants. There were significant differences in most of the participants' characteristics including diabetes prevalence and $\mathrm{PM}_{10}$ exposure, but the prevalence of these characteristics were generally higher among the included participants compared to the excluded ones (Additional file 1: Table S1). The IL6 -572G > C and IL6 -174G > C genotypes, and IRS were similarly distributed between both groups (Additional file 1: Table S1).

The positive association between air pollutants and diabetes, which we previously observed in our previous study of 6392 participants at this follow-up study [28], persisted in the present sample. The adjusted odds of diabetes increased by $47 \%$ (95 \% CI: 1.21, 1.78) per 
Table 2 Characteristics of participants by IL6 -572 G>C and IL6-174 G>C genotypes

\begin{tabular}{|c|c|c|c|c|c|c|c|}
\hline & \multicolumn{3}{|l|}{ IL6 -572 G>C } & \multicolumn{4}{|l|}{ IL6 -174 G>C } \\
\hline & $\overline{G G}(N=3891)$ & $G C+C C(N=519)$ & $P\left(\mathrm{Chi}^{2}\right)$ & $\overline{G G}(N=1618)$ & $G C(N=2110)$ & $C C(N=682)$ & $P\left(\mathrm{Chi}^{2}\right)$ \\
\hline \multicolumn{8}{|l|}{ Proportion (\%) } \\
\hline Females & 48.4 & 49.1 & 0.768 & 48.3 & 48.1 & 50.6 & 0.509 \\
\hline Education $\geq 9$ years & 94.9 & 93.2 & 0.107 & 94.4 & 94.9 & 95.0 & 0.721 \\
\hline Never-smokers & 44.3 & 45.6 & 0.490 & 42.4 & 44.8 & 48.1 & 0.036 \\
\hline Passive smoke exposure & 46.4 & 46.6 & 0.927 & 48.6 & 45.4 & 44.4 & 0.078 \\
\hline Occupational VGDF exposure & 42.8 & 42.4 & 0.845 & 43.9 & 42.6 & 40.9 & 0.398 \\
\hline Alcohol intake $\leq 1$ glass/day & 91.0 & 91.4 & 0.620 & 89.8 & 91.2 & 93.0 & 0.050 \\
\hline Alcohol intake $>$ 1glass/day & 9.0 & 9.6 & & 10.2 & 8.8 & 7.0 & \\
\hline Portion of raw vegetables $\leq 3$ days/week & 18.2 & 20.8 & 0.150 & 17.4 & 19.1 & 19.4 & 0.351 \\
\hline Portion of raw vegetables $>3$ days/week & 81.8 & 79.2 & & 82.6 & 80.9 & 80.6 & \\
\hline Portion of fruits $\leq 3$ days/week & 35.8 & 35.6 & 0.923 & 35.0 & 36.2 & 36.7 & 0.657 \\
\hline Portion of fruits $>3$ days/week & 64.2 & 64.4 & & 65.0 & 63.8 & 63.3 & \\
\hline Portion of citrus fruits $\leq 3$ days/week & 64.2 & 64.0 & 0.909 & 64.2 & 63.9 & 64.8 & 0.917 \\
\hline Portion of citrus fruits $>3$ days/week & 35.8 & 36.0 & & 35.8 & 36.1 & 35.2 & \\
\hline Vigorous physical activity $<0.5 \mathrm{~h} /$ week & 35.5 & 37.2 & 0.449 & 37.3 & 34.6 & 34.2 & 0.082 \\
\hline Vigorous physical activity $\geq 0.5 \mathrm{~h} /$ week & 64.5 & 62.8 & & 62.1 & 65.4 & 65.8 & \\
\hline Diabetes cases & 5.5 & 6.7 & 0.260 & 6.2 & 5.5 & 4.8 & 0.430 \\
\hline Areas: Basel & 11.5 & 12.9 & 0.062 & 10.5 & 11.6 & 14.8 & $<0.001$ \\
\hline Wald & 19.1 & 19.1 & & 19.0 & 18.6 & 20.8 & \\
\hline Davos & 7.7 & 6.9 & & 7.5 & 7.9 & 7.0 & \\
\hline Lugano & 12.6 & 14.6 & & 15.0 & 12.6 & 8.4 & \\
\hline Montana & 11.1 & 6.9 & & 9.2 & 11.2 & 12.0 & \\
\hline Payerne & 13.1 & 12.7 & & 13.3 & 12.1 & 15.2 & \\
\hline Aarau & 16.6 & 19.3 & & 16.9 & 17.6 & 14.4 & \\
\hline Geneva & 8.4 & 7.5 & & 8.6 & 8.4 & 7.3 & \\
\hline Means (SD) & & & $T$-test & & & & ANOVA \\
\hline Age (years) & $51.8(11)$ & $51.3(11)$ & 0.269 & $51.8(11)$ & $51.8(11)$ & $51.5(11)$ & 0.732 \\
\hline $\mathrm{BMI}\left(\mathrm{kg} / \mathrm{m}^{2}\right)$ & $25.8(4.3)$ & $26.3(4.3)$ & 0.025 & $26.0(4.3)$ & $25.8(4.3)$ & $25.9(4.3)$ & 0.152 \\
\hline Neighborhood SEl & $63.7(10)$ & $63.8(10)$ & 0.827 & $63.5(10)$ & $63.9(10)$ & $63.8(9)$ & 0.455 \\
\hline 10-year mean $\mathrm{PM}_{10}\left(\mathrm{\mu g} / \mathrm{m}^{3}\right)$ & $21.8(7.3)$ & $22.8(7.2)$ & 0.005 & $22.3(7.4)$ & $21.9(7.3)$ & $21.5(6.9)$ & 0.030 \\
\hline Pack-years of smoking ${ }^{a}$ & $0(14)$ & $0.1(16)$ & 0.296 & $0.3(16)$ & $0(16)$ & $0(14)$ & 0.524 \\
\hline
\end{tabular}

VGDF: vapours, gases, dusts and fumes; SD: standard deviation; BMI: body mass index; SEl: socio-economic index; $\mathrm{PM}_{10}$ : particulate matter <10 $\mu \mathrm{m}$ in diameter. avalues represent median (interquartile range) and $P$-values represent significance level of median test

$10 \mathrm{ug} / \mathrm{m}^{3}$ of exposure to $\mathrm{PM}_{10}$. We did not observe any significant association between the candidate IL6 SNPs and diabetes, across three genetic models. We also did not observe significant associations between IRS and diabetes in our sample (Additional file 1: Table S2).

Stratified by genotypes, the association between $\mathrm{PM}_{10}$ and diabetes was most pronounced among carriers of the major GG pro-inflammatory alleles for both polymorphisms (Fig. 2). We observed significant interactions between $\mathrm{PM}_{10}$ and IL6 -572G > C in the additive and recessive models which became more significant in the models accounting for potential selection bias by IPW and remained significant following Bonferroni correction at $P=0.01(0.05 / 5)$ (Table 3$)$. We did not observe any statistically significant interactions with IL6 -174G > C across genetic models and adjustment for potential selection bias by IPW (Table 3). We observed a positive trend in the association between $\mathrm{PM}_{10}$ and diabetes across levels of IRS (Fig. 2). Carriers of four pro-inflammatory G alleles had the highest odds of diabetes per $10 \mathrm{ug} / \mathrm{m}^{3}$ increase in exposure to $\mathrm{PM}_{10}\left(P_{\text {interaction }}=0.10\right)($ Fig. 2). Compared to carriers of two pro-inflammatory $\mathrm{G}$ alleles, 


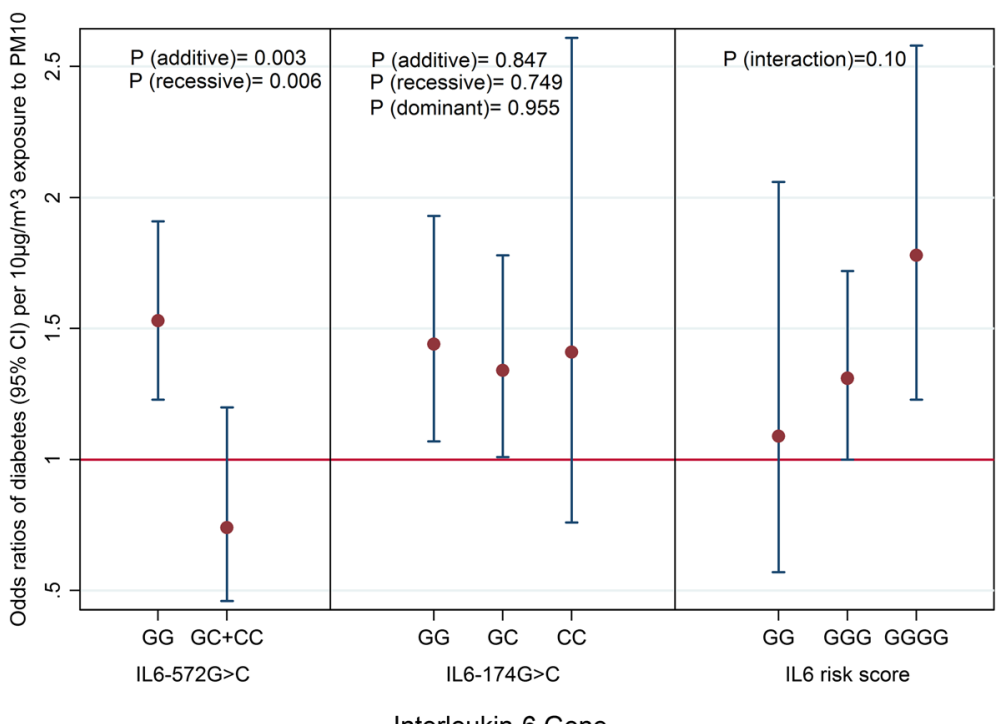

Fig. 2 Interaction between $\mathrm{PM}_{10}$ and $/ L 6$ polymorphisms on odds of diabetes. Odds ratio values represent percentage increase of odds of diabetes per $10 \mu \mathrm{g} / \mathrm{m}^{3}$ increase in $\mathrm{PM}_{10}$ exposure adjusted for potential selection bias. $\mathrm{PM}_{10}$ : particulate matter $<10 \mu \mathrm{m}$ in diameter. All associations are adjusted for body mass index, age, sex, socio-economic status, smoking habits, consumption of alcohol, fruits and vegetables, physical activity and genome-wide population stratification. Study area was treated as a random effect in all models

Table 3 Associations and interactions between $\mathrm{PM}_{10}$ and candidate SNPs on odds of diabetes, applying inverse probability weighting (IPW) to account for potential selection bias

\begin{tabular}{|c|c|c|c|c|c|}
\hline Genotype & $\begin{array}{l}\text { Genotype-specific } \mathrm{PM}_{10} \text { and diabetes } \\
\text { association OR }(95 \% \mathrm{Cl})\end{array}$ & $P$-value & $P$-value of interaction ${ }^{* *}$ & $P$-value of interaction ${ }^{* * *}$ & $P$-value of interaction ${ }^{* * * *}$ \\
\hline \multicolumn{6}{|c|}{ IL6 - $572 \mathrm{G}>\mathrm{C}$} \\
\hline \multicolumn{6}{|c|}{ Adjusted model without IPW } \\
\hline GG & $1.53(1.22,1.92)$ & $<0.001$ & 0.031 & n.d. & 0.058 \\
\hline $\mathrm{GC}+\mathrm{CC}$ & $0.87(0.51,1.49)$ & 0.618 & & & \\
\hline \multicolumn{6}{|c|}{ Adjusted model applying IPW } \\
\hline GG & $1.53(1.23,1.91)$ & $<0.001$ & 0.003 & n.d. & 0.006 \\
\hline $\mathrm{GC}+\mathrm{CC}$ & $0.74(0.46,1.20)$ & 0.225 & & & \\
\hline \multicolumn{6}{|c|}{ IL6 -174G >C } \\
\hline \multicolumn{6}{|c|}{ Adjusted model without IPW } \\
\hline GG & $1.49(1.09,2.04)$ & 0.012 & 0.763 & 0.966 & 0.645 \\
\hline GC & $1.35(1.01,1.80)$ & 0.046 & & & \\
\hline CC & $1.43(0.80,2.54)$ & 0.226 & & & \\
\hline \multicolumn{6}{|c|}{ Adjusted model applying IPW } \\
\hline GG & $1.44(1.07,1.93)$ & 0.016 & 0.847 & 0.955 & 0.749 \\
\hline GC & $1.34(1.01,1.78)$ & 0.044 & & & \\
\hline CC & $1.41(0.76,2.61)$ & 0.226 & & & \\
\hline
\end{tabular}

Adjusted models include age, sex, educational attainment, neighborhood-level socio-economic status, smoking status, pack-years of smoking, exposure to passive smoke and occupational dusts and fumes, dietary fibre intake, alcohol consumption, physical activity, body mass index (BMI), $\mathrm{PM}_{10}$. Study area was treated as random effects in all models. OR: odds ratio; Cl: confidence intervals; OR values represent percent increase in odds of diabetes per $10 \mu \mathrm{\mu g} / \mathrm{m}^{3}$ increase in $\mathrm{PM}_{10}$ exposure. $\mathrm{PM}_{10}$ : particulate matter $<10 \mu \mathrm{m}$ in diameter. ${ }^{*}$-value of genotype specific association between $\mathrm{PM}_{10}$ and diabetes. ${ }^{* *}$ additive model (per $\mathrm{G}$ allele); ${ }^{* * * *}$ dominant model (GG + GC vs. CC); ${ }^{* * * *}$ recessive model (GG vs. GC + CC); n.d: not done due to the few number of $\mathrm{CC}$ allele carriers 
carriers of four risk alleles had $60 \%$ (95\% CI: $-15 \%$, $197 \%$ ) higher odds of diabetes per $10 \mathrm{ug} / \mathrm{m}^{3}$ increase in exposure to $\mathrm{PM}_{10}$. These interactions were largely stable to confounder adjustments.

Sensitivity analyses showed very similar results. Defining diabetes according to each of the classification criteria showed very similar results with significant interactions in the additive and recessive genetic models (Table 4). Odds of diabetes identified through blood tests among GG genotype carriers remained positive but less significant (Table 4). Applying a logistic regression model with random slopes by study area also did not change estimates of the interaction between $\mathrm{PM}_{10}$ and the candidate SNPs on prevalent diabetes, but changed the estimated association between $\mathrm{PM}_{10}$ and diabetes among the pro-inflammatory GG genotype carriers (Table 4). In a sub-sample of 2825 non-asthmatic participants who were genotyped using the Illumina Human Omni Exome Express Bead Chip, where IL6 -572G > C was in HWE (Pearson's correlation $\mathrm{R}^{2}$ between both SNPs =1), associations persisted among pro-inflammatory GG carriers [OR: $1.64(1.24,2.16)]$ and interactions persisted in the models accounting for potential selection bias $\left(P_{\text {(additive) }}=0.053 ; P_{\text {(recessive })=} 0.048\right)$.

\section{Discussion}

We found a modifying effect of IL6 $-572 \mathrm{G}>\mathrm{C}$ polymorphism on the association between air pollutants and diabetes, where carriers of the pro-inflammatory GG genotype were most susceptible. These associations were highly stable to confounder adjustments and remained robust across several sensitivity analyses. The lack of interaction with IL6 -174G $>C$ is supported by the fact that both SNPs are not in linkage disequilibrium. Combining both SNPs into an IRS showed increased association among participants at high genetic risk of inflammation.

The lack of association between $\mathrm{PM}_{10}$ and $\mathrm{DM}$ among the GG genotype carriers in the fixed effect model could be attributed to variation of $\mathrm{PM}_{10}$ constituents across different areas (Pearson's R for $\mathrm{PM}_{10}$ crustal components across four SAPALDIA areas $=0.34$ ) [39]. Due to the fact that the likelihood-ratio tests for interactions between $\mathrm{PM}_{10}$ and study area (also between SNP and study area) were non-significant $(P>0.2)$, and that the goal of SAPALDIA air pollution studies is to capture the between area differences in health effects which cannot be explained by the fixed factors in the models, we performed the main analyses using area as a random covariate. In addition, applying the fixed effects model did not change our estimates of interaction between IL6 polymorphisms and $\mathrm{PM}_{10}$ which is our main interest in this study. The reduced significance of interactions among those reporting the use of diabetes medication is most likely to be due to under-reporting of medication use.
The absence of any significant association between the IL6 polymorphisms and diabetes in our sample may be due to our inability to differentiate T1D from T2D, or the relatively small number of cases compared to other studies [26]. Thus, our observation of a significant interaction is surprising given the limited number of cases in our study.

To our knowledge, this is the first evidence on geneair pollution interaction in adult diabetes. Until now, gene-air pollution interaction studies focused on respiratory and cardiovascular outcomes, exploring diverse candidate genes or polymorphisms, pollutants and outcomes [40-42]. Many of the interacting genes including IL6, regulate systemic oxidative stress and inflammatory pathways [41, 43]. IL6 is one of the genes involved in systemic inflammation by regulating or inducing the production of inflammatory cytokines such as IL-6 and CRP. In-vitro studies also show that exposure to particulate matter induces IL6 and CRP gene expression in epithelial and macrophage cell lines [14, 44, 45]. In addition, polymorphisms on IL6 have been shown to interact with acute exposure to carbon monoxide and nitrogen dioxide, in eliciting plasma IL-6 response [43].

Our results support the hypothesis that exposure to air pollution may contribute to diabetes aetiology through inflammatory pathways. Since we have analysed two $\mathrm{C} / \mathrm{G}$ polymorphisms located in the promoter region of IL6 in our study, a potential mechanism of action could be related to changes in DNA methylation at these sites, affecting IL6 gene expression. Air pollution exposure was positively associated with methylation of IL6 in elderly men [46]. Hypomethylation of IL6 was associated with raised levels of serum IL-6 in patients with rheumatoid arthritis [47], and with body weight among diabetes patients [48]. In contrast, increased methylation of IL6 was associated with risk of obesity [49] and body weight among patients without diabetes [48]. Furthermore there is suggestive evidence on a potential link between epigenetic changes at inflammatory genes (including IL6) and diabetes $[50,51]$. While the evidence supports a role of IL6 methylation with regard to both, air pollution and diabetes, the relevance of hyper- versus hypomethylation and the association with the IL6 SNPs studied here needs further clarification.

Our study has major strengths. It provides first evidence to our knowledge on gene-air pollution interactions on diabetes risk. It derives from the large database of the population-based SAPALDIA cohort, with well characterized phenotypes, genotypes and lifestyle characteristics. Our air pollution estimates were assigned to participants' residences and derived from validated models which have been applied to other studies. [33] By taking into account residential histories of participants, we could compute individual estimates of long- 
Table 4 Other Sensitivity Analyses

\begin{tabular}{|c|c|c|c|c|c|c|}
\hline Sensitivity analysis & Genotype & Adjusted OR (95 \% Cl) & $P$-value & $P$-value & $P$-value ${ }^{* * *}$ & $P$-value ${ }^{* * * *}$ \\
\hline \multirow{7}{*}{$\begin{array}{l}\text { Diabetes defined as self-reported physician } \\
\text { diagnosis and medication use } \\
[\text { N(diabetes })=196]\end{array}$} & IL6-572G >C & & & & & \\
\hline & GG & $1.41(1.11,1.79)$ & 0.005 & 0.001 & n.d. & 0.004 \\
\hline & $\mathrm{GC}+\mathrm{CC}$ & $0.63(0.38,1.04)$ & 0.070 & & & \\
\hline & $I L 6-174 G>C$ & & & & & \\
\hline & GG & $1.23(0.88,1.71)$ & 0.222 & 0.931 & 0.797 & 0.794 \\
\hline & GC & $1.33(0.98,1.81)$ & 0.065 & & & \\
\hline & CC & $1.17(0.58,2.35)$ & 0.669 & & & \\
\hline \multirow{7}{*}{$\begin{array}{l}\text { Diabetes defined as self-reported physician } \\
\text { diagnosis only [N(diabetes) }=193]\end{array}$} & IL6 -572G >C & & & & & \\
\hline & GG & $1.43(1.13,1.83)$ & 0.003 & 0.008 & n.d. & 0.003 \\
\hline & $\mathrm{GC}+\mathrm{CC}$ & $0.63(0.38,1.04)$ & 0.072 & & & \\
\hline & IL6 -174G >C & & & & & \\
\hline & GG & $1.23(0.88,1.71)$ & 0.226 & 0.881 & 0.749 & 0.694 \\
\hline & GC & $1.38(1.01,1.88)$ & 0.041 & & & \\
\hline & $\mathrm{CC}$ & $1.16(0.57,2.33)$ & 0.680 & & & \\
\hline \multirow{7}{*}{$\begin{array}{l}\text { Diabetes defined as self-reported use of } \\
\text { diabetes medication only [N(diabetes) }=125]\end{array}$} & IL6 -572G >C & & & & & \\
\hline & GG & $1.25(0.95,1.66)$ & 0.113 & 0.008 & n.d. & 0.031 \\
\hline & $\mathrm{GC}+\mathrm{CC}$ & $0.49(0.22,1.10)$ & 0.085 & & & \\
\hline & IL6 -174G >C & & & & & \\
\hline & GG & $1.10(0.72,1.66)$ & 0.666 & 0.954 & 0.600 & 0.803 \\
\hline & GC & $1.24(0.86,1.78)$ & 0.246 & & & \\
\hline & CC & $0.90(0.36,2.28)$ & 0.829 & & & \\
\hline \multirow{7}{*}{$\begin{array}{l}\text { Diabetes cases identified from blood } \\
\text { tests only [N (diabetes) }=184]\end{array}$} & IL6 -572G >C & & & & & \\
\hline & GG & $1.65(1.27,2.13)$ & $<0.001$ & 0.002 & n.d. & 0.006 \\
\hline & $\mathrm{GC}+\mathrm{CC}$ & $0.70(0.39,1.25)$ & 0.223 & & & \\
\hline & IL6 -174G >C & & & & & \\
\hline & GG & $1.46(1.04,2.06)$ & 0.030 & 0.738 & 0.553 & 0.962 \\
\hline & GC & $1.41(1.00,1.99)$ & 0.052 & & & \\
\hline & $\mathrm{CC}$ & $1.83(0.86,3.90)$ & 0.118 & & & \\
\hline \multirow{7}{*}{$\begin{array}{l}\text { Model applying random slopes for } \\
\text { study areas [N(diabetes) }=252]\end{array}$} & IL6 -572G >C & & & & & \\
\hline & GG & $0.92(0.44,1.92)$ & 0.819 & 0.004 & n.d. & 0.008 \\
\hline & $\mathrm{GC}+\mathrm{CC}$ & $0.44(0.19,1.05)$ & 0.065 & & & \\
\hline & IL6 -174G >C & & & & & \\
\hline & GG & $0.86(0.41,1.83)$ & 0.704 & 0.814 & 0.928 & 0.687 \\
\hline & GC & $0.78(0.36,1.70)$ & 0.540 & & & \\
\hline & $\mathrm{CC}$ & $0.85(0.33,2.20)$ & 0.735 & & & \\
\hline
\end{tabular}

Adjusted models include age, sex, educational attainment, neighborhood-level socio-economic status, smoking status, pack-years of smoking, exposure to passive smoke and occupational dusts and fumes, dietary fibre intake, alcohol consumption, physical activity, body mass index (BMI), $\mathrm{PM}_{10}$. Study area was treated as random effects in all models except the model with random slopes for study area.OR: odds ratio; Cl: confidence intervals; OR values represent percent increase in odds of diabetes per $10 \mu \mathrm{g} / \mathrm{m} 3$ increase in $\mathrm{PM}_{10}$ exposure. $\mathrm{PM}_{10}$ : particulate matter $<10 \mu \mathrm{m}$ in diameter; n.d: not done due to very low sample size for CCgenotype. ${ }^{*} P$-value of genotype specific association between air pollutant and diabetes. ${ }^{* *}$ additive model (per C allele); ${ }^{* * *}$ dominant model $\left(\mathrm{GG}+\mathrm{GC}\right.$ vs. CC); ${ }^{* * *}$ recessive model $(\mathrm{GC}+\mathrm{CC}$ vs.GG)

term exposure to air pollution, which is a crucial in understanding disease development and progression attributable to air pollution. We minimized outcome misclassification by identifying undiagnosed diabetes cases through additional blood tests.
Our study also has limitations. It has a cross-sectional design hence we cannot infer causality of observed associations. We tried to improve this by estimating air pollution exposure in the ten years prior to the survey where diabetes was assessed. In addition, an exploratory 
analysis excluding 17 diabetes cases who reported to have started using diabetes medication before 1991 gave very similar results. We could not differentiate T1D from T2D cases and therefore have misclassified a few cases (on the average $<10 \%$ as T2D instead of T1D). [31].

One of our functional SNPs of interest, IL6 -572G > C, was not in HWE (Table 1). SNPs may deviate from HWE due to genotyping error, population stratification or population selection $[52,53]$. Therefore, we assessed quality control by genotyping a subsample of our participants using an alternative genotyping array. There was no indication of genotyping errors since both SNPs had a perfect correlation between the two genotyping rounds. Also, we adjusted for population stratification in our study population using genome-wide principal components. It has been shown that SNPs may still deviate from HWE despite controlling for the aforementioned reasons [53]. It is also important to note that IL6 -572G > C was not in HWE in a study linking it to T2D in Europeans [38] and the minor alleles were similarly distributed between the reference study $(\mathrm{MAF}=$ $5 \%$ ) and our study (MAF = $7 \%$ ). Furthermore, the genotype frequencies were also similarly distributed [Diabetes cases- GG: $90.6 \%$, GC: $9 \%$, CC: $0.4 \%$; No diabetes - GG: $86.7 \%$, GC: $12.6 \%$, CC: $0.7 \%$ vs. Table 1 ). We additionally assessed public databases to identify any potential interference on our PCR probe by nearby SNPs but found no evidence for such. We did not measure plasma IL-6 concentrations in our participants due to lack of funds, precluding our assessment of association between candidate SNPs and serum IL-6 levels, but there was a positive correlation between both SNPs and mean high-sensitivity C-reactive proteins (hs-CRP) measured at this first followup (IL6 -572G > C-CC: 1.28 g/l, GC: 1.45 g/l, GG: 1.58 g/l and IL6 -174G > C-CC: 1.58 g/l; GC: 1.53 g/l; GG: $1.60 \mathrm{~g} / \mathrm{l}$ ). The larger differences in hs-CRP levels associated with IL6 -572G > C agrees with its larger interaction effect. Lastly, our study had sample size limitations, especially among the CC genotype carriers of IL6 -572G > C, limiting the statistical power to detect more associations. Despite this, we made some statistically significant observations.

\section{Conclusions}

Our findings suggest that homozygous carriers of the common pro-inflammatory major ' $G$ ' allele of IL6 $-572 \mathrm{G}>\mathrm{C}$ polymorphism may be more susceptible to the diabetogenic effects of particulate matter, supporting the relevance of inflammatory pathways in the relationship between air pollution and diabetes. If confirmed, our results are of high public health relevance considering the ubiquity of the major $\mathrm{G}$ alleles, which put a substantial proportion of the population at risk for the development of diabetes as a result of exposure to air pollution. Our results therefore call for replication by other longitudinal population-based studies with adequate air pollution, genotype and diabetes information.

\section{Additional file}

Additional file 1: Table S1. Characteristics of included and excluded participants. Table S2. Association between functional IL6 polymorphisms and diabetes. (DOCX $27 \mathrm{~kb}$ )

\section{Abbreviations}

BMI: body mass index; DNA: Deoxyribonucleic acid;

EDTA: ethylenediaminetetraacetic acid; HbA1C: Glycosylated haemoglobin; hs-CRP: high-sensitivity C-reactive proteins; HWE: Hardy-Weinberg equilibrium; IL6: Interleukin-6 gene; IL-6: Interleukin-6 cytokine; $\mathrm{NO}_{2}$ : nitrogen dioxide; PM $_{10}$ : Particulate matter with diameter less than 10 microns;

SAPALDIA: Swiss cohort study on air pollution and lung and heart diseases in adults; SNP: single nucleotide polymorphism; T1D: Type 1 diabetes; T2D: Type 2 diabetes..

\section{Competing interests}

All authors declare no actual or potential financial and non-financial interests. The funders played no role in the design or the outcome of this study.

\section{Authors' contributions}

All authors contributed equally to the conception of this study and the development of this manuscript. All authors read and approved the final manuscript.

\section{Acknowledgements}

The Swiss National Science Foundation (grants no 33CS30-148470/1, 33CSCO-134276/1, 33CSCO-108796, 324730_135673, 3247BO-104283, 3247BO-104288, 3247BO-104284, 3247-065896, 3100-059302, 3200-052720, 3200-042532, 4026-028099, PMPDP3_129021/1, PMPDP3_141671/1), the Federal Office for the Environment, the Federal Office of Public Health, the Federal Office of Roads and Transport, the canton's government of Aargau, Basel-Stadt, Basel-Land, Geneva, Luzern, Ticino, Valais, and Zürich, the Swiss Lung League, the canton's Lung League of Basel Stadt/ Basel Landschaft, Geneva, Ticino, Valais, Graubünden and Zurich, Stiftung ehemals Bündner Heilstätten, SUVA, Freiwillige Akademische Gesellschaft, UBS Wealth Foundation, Talecris Biotherapeutics GmbH, Abbott Diagnostics, European Commission 018996 (GABRIEL), Wellcome Trust WT 084703MA

The study could not have been done without the help of the study participants, technical and administrative support and the medical teams and field workers at the local study sites.

\section{Current SAPALDIA Team}

Study directorate: NM Probst-Hensch (PI; e/g); T Rochat (p), C Schindler (s), N Künzli (e/exp), JM Gaspoz (c).

Scientific team: JC Barthélémy (c), W Berger ( $g$ ), R Bettschart (p), A Bircher (a), C Brombach (n), PO Bridevaux (p), L Burdet (p), Felber Dietrich D (e), M Frey (p), U Frey (pd), MW Gerbase (p), D Gold (e), E de Groot (c), W Karrer (p), F Kronenberg (g), B Martin (pa), A Mehta (e), D Miedinger (o), M Pons (p), F Roche (c), T Rothe (p), P Schmid-Grendelmeyer (a), D Stolz (p), A SchmidtTrucksäss (pa), J Schwartz (e), A Turk (p), A von Eckardstein (cc), E Zemp Stutz (e). Scientific team at coordinating centers: M Adam (e), I Aguilera (exp), S Brunner (s), D Carballo (c), S Caviezel (pa), I Curjuric (e), A Di Pascale (s), J Dratva (e), R Ducret (s), E Dupuis Lozeron (s), M Eeftens (exp), I Eze (e), E Fischer (g), M Foraster (e), M Germond (s), L Grize (s), S Hansen (e), A Hensel (s), M Imboden (g), A Ineichen (exp), A Jeong (g), D Keidel (s), A Kumar (g), N Maire (s), A Mehta (e), R Meier (exp), E Schaffner (s), T Schikowski (e), M Tsai (exp). (a) allergology, (c) cardiology, (cc) clinical chemistry, (e) epidemiology, (exp) exposure, (g) genetic and molecular biology, (m) meteorology, (n) nutrition, (o) occupational health, (p) pneumology, (pa) physical activity, (pd) pediatrics, (s) statistics

Local fieldworkers : Aarau: S Brun, G Giger, M Sperisen, M Stahel, Basel: C Bürli, C Dahler, N Oertli, I Harreh, F Karrer, G Novicic, N Wyttenbacher, Davos: A Saner, P Senn, R Winzeler, Geneva: F Bonfils, B Blicharz, C Landolt, J Rochat, Lugano: S Boccia, E Gehrig, MT Mandia, G Solari, B Viscardi, Montana: AP 
Bieri, C Darioly, M Maire, Payerne: F Ding, P Danieli A Vonnez, Wald: D Bodmer, E Hochstrasser, R Kunz, C Meier, J Rakic, U Schafroth, A Walder Administrative staff: N Bauer Ott, C Gabriel, R Gutknecht.

\section{Author details}

${ }^{1}$ Swiss Tropical and Public Health Institute, Basel, Switzerland. ${ }^{2}$ University of Basel, Basel, Switzerland. ${ }^{3}$ Karolinska Institutet, Stockholm, Sweden. ${ }^{4}$ Institute of Clinical Chemistry, University Hospital Zurich, Zurich, Switzerland. ${ }^{5} \mathrm{Clinic}$ of Pneumology and Respiratory Cell Research, University Hospital Basel, Basel, Switzerland. ${ }^{6}$ Faculty of Medicine, University of Geneva, Geneva, Switzerland. ${ }^{7}$ Zürcher Höhenklinik Wald, Faltigberg-Wald, Switzerland. ${ }^{8}$ Division of Genetic Epidemiology, Department of Medical Genetics, Molecular and Clinical Pharmacology, Medical University of Innsbruck, Innsbruck, Austria. ${ }^{9}$ Department of Epidemiology and Public Health, Swiss Tropical and Public Health Institute, Socinstrasse 57, CH-4002 Basel, Switzerland.

\section{Received: 23 October 2015 Accepted: 8 February 2016 Published online: 24 February 2016}

\section{References}

1. Eze IC, Hemkens LG, Bucher HC, Hoffmann B, Schindler C, Kunzli N, et al. Association between Ambient Air Pollution and Diabetes Mellitus in Europe and North America: Systematic Review and Meta-Analysis. Environ Health Perspect. 2015;123(5):381-9.

2. Eze IC, Schaffner E, Fischer E, Schikowski T, Adam M, Imboden M, et al. Long-term air pollution exposure and diabetes in a population-based Swiss cohort. Environ Int. 2014;70:95-105.

3. Weinmayr G, Hennig F, Fuks K, Nonnemacher M, Jakobs H, Mohlenkamp S, et al. Long-term exposure to fine particulate matter and incidence of type 2 diabetes mellitus in a cohort study: effects of total and traffic-specific air pollution. Environ Health. 2015;14:53.

4. Rajagopalan S, Brook RD. Air pollution and type 2 diabetes: mechanistic insights. Diabetes. 2012;61(12):3037-45.

5. Liu C, Ying Z, Harkema J, Sun Q, Rajagopalan S. Epidemiological and experimental links between air pollution and type 2 diabetes. Toxicol Pathol. 2013;41(2):361-73.

6. Hennig F, Fuks K, Moebus S, Weinmayr G, Memmesheimer M, Jakobs H, et al. Association between source-specific particulate matter air pollution and hs-CRP: local traffic and industrial emissions. Environ Health Perspect. 2014; 122(7):703-10.

7. Li Y, Rittenhouse-Olson K, Scheider WL, Mu L. Effect of particulate matter air pollution on C-reactive protein: a review of epidemiologic studies. Rev Environ Health. 2012;27(2-3):133-49.

8. Brocato J, Sun H, Shamy M, Kluz T, Alghamdi MA, Khoder MI, et al. Particulate matter from Saudi Arabia induces genes involved in inflammation, metabolic syndrome and atherosclerosis. J Toxicol Environ Health. 2014;77(13):751-66.

9. Hoffmann B, Moebus S, Dragano N, Stang A, Mohlenkamp S, Schmermund A, et al. Chronic residential exposure to particulate matter air pollution and systemic inflammatory markers. Environ Health Perspect. 2009;117(8):1302-8.

10. Hajat A, Allison M, Diez-Roux AV, Jenny NS, Jorgensen NW, Szpiro AA, et al. Long-term Exposure to Air Pollution and Markers of Inflammation, Coagulation, and Endothelial Activation: A Repeat-measures Analysis in the Multi-Ethnic Study of Atherosclerosis (MESA). Epidemiology. 2015;26(3):310-20.

11. Bind MA, Baccarelli A, Zanobetti A, Tarantini L, Suh H, Vokonas P, et al. Air pollution and markers of coagulation, inflammation, and endothelial function: associations and epigene-environment interactions in an elderly cohort. Epidemiology. 2012;23(2):332-40.

12. Budinger GR, McKell JL, Urich D, Foiles N, Weiss I, Chiarella SE, et al. Particulate matter-induced lung inflammation increases systemic levels of PAl-1 and activates coagulation through distinct mechanisms. PLoS One. 2011;6(4):e18525.

13. Mutlu GM, Green D, Bellmeyer A, Baker CM, Burgess Z, Rajamannan N, et al. Ambient particulate matter accelerates coagulation via an IL-6-dependent pathway. J Clin Invest. 2007;117(10):2952-61.

14. Quay JL, Reed W, Samet J, Devlin RB. Air pollution particles induce IL-6 gene expression in human airway epithelial cells via NF-kappaB activation. Am J Respir Cell Mol Biol. 1998;19(1):98-106.

15. Kristiansen OP, Mandrup-Poulsen T. Interleukin-6 and diabetes: the good, the bad, or the indifferent? Diabetes. 2005;54 Suppl 2:S114-24.
16. Pradhan AD, Manson JE, Rifai N, Buring JE, Ridker PM. C-reactive protein, interleukin 6, and risk of developing type 2 diabetes mellitus. JAMA. 2001; 286(3):327-34

17. Spranger J, Kroke A, Mohlig M, Hoffmann K, Bergmann MM, Ristow M, et al. Inflammatory cytokines and the risk to develop type 2 diabetes: results of the prospective population-based European Prospective Investigation into Cancer and Nutrition (EPIC)-Potsdam Study. Diabetes. 2003;52(3):812-7.

18. Sandler S, Bendtzen K, Eizirik DL, Welsh M. Interleukin-6 affects insulin secretion and glucose metabolism of rat pancreatic islets in vitro. Endocrinology. 1990;126(2):1288-94.

19. Lagathu C, Bastard JP, Auclair M, Maachi M, Capeau J, Caron M. Chronic interleukin-6 (IL-6) treatment increased IL-6 secretion and induced insulin resistance in adipocyte: prevention by rosiglitazone. Biochem Biophys Res Comm. 2003;311(2):372-9.

20. Fasshauer M, Kralisch S, Klier M, Lossner U, Bluher M, Klein J, et al. Adiponectin gene expression and secretion is inhibited by interleukin- 6 in 3 T3-L1 adipocytes. Biochem Biophys Res Comm. 2003;301(4):1045-50.

21. Daniele G, Guardado Mendoza R, Winnier D, Fiorentino TV, Pengou Z, Cornell J, et al. The inflammatory status score including IL-6, TNF-alpha, osteopontin, fractalkine, MCP-1 and adiponectin underlies whole-body insulin resistance and hyperglycemia in type 2 diabetes mellitus. Acta Diabetol. 2014;51(1):123-31.

22. Ruge T, Lockton JA, Renstrom F, Lystig T, Sukonina V, Svensson MK, et al. Acute hyperinsulinemia raises plasma interleukin- 6 in both nondiabetic and type 2 diabetes mellitus subjects, and this effect is inversely associated with body mass index. Metabolism. 2009;58(6):860-6.

23. Brull DJ, Montgomery HE, Sanders J, Dhamrait S, Luong L, Rumley A, et al. Interleukin-6 gene - $174 \mathrm{~g}>\mathrm{c}$ and $-572 \mathrm{~g}>\mathrm{c}$ promoter polymorphisms are strong predictors of plasma interleukin-6 levels after coronary artery bypass surgery. Arterioscler Thromb Vasc Biol. 2001;21(9):1458-63.

24. Sanderson SC, Kumari M, Brunner EJ, Miller MA, Rumley A, Lowe GD, et al. Association between IL6 gene variants -174G $>C$ and $-572 G>C$ and serum IL-6 levels: interactions with social position in the Whitehall $\|$ cohort. Atherosclerosis. 2009;204(2):459-64.

25. Sainz J, Perez E, Gomez-Lopera S, Lopez-Fernandez E, Moratalla L, Oyonarte S, et al. Genetic variants of IL6 gene promoter influence on C-reactive protein levels but are not associated with susceptibility to invasive pulmonary aspergillosis in haematological patients. Cytokine. 2008;41(3):268-78.

26. Yin $\mathrm{YW}$, Sun $\mathrm{QQ}$, Zhang BB, Hu AM, Liu HL, Wang Q, et al. Association between the interleukin-6 gene $-572 \mathrm{C} / \mathrm{G}$ polymorphism and the risk of type 2 diabetes mellitus: a meta-analysis of 11,681 subjects. Ann Hum Genet. 2013;77(2):106-14.

27. Huth C, Heid IM, Vollmert C, Gieger C, Grallert H, Wolford JK, et al. IL6 gene promoter polymorphisms and type 2 diabetes: joint analysis of individual participants' data from 21 studies. Diabetes. 2006;55(10):2915-21.

28. Eze IC, Schaffner E, Zemp E, von Eckardstein A, Turk A, Bettschart R, et al. Environmental tobacco smoke exposure and diabetes in adult neversmokers. Environ Health. 2014;13:74.

29. Martin BW, Ackermann-Liebrich U, Leuenberger P, Kunzli N, Stutz EZ, Keller R, et al. SAPALDIA: methods and participation in the cross-sectional part of the Swiss Study on Air Pollution and Lung Diseases in Adults. Soz Praventivmed. 1997:42(2):67-84

30. Ackermann-Liebrich U, Kuna-Dibbert B, Probst-Hensch NM, Schindler C, Felber Dietrich D, Stutz EZ, et al. Follow-up of the Swiss Cohort Study on Air Pollution and Lung Diseases in Adults (SAPALDIA 2) 1991-2003: methods and characterization of participants. Sozi Praventivmed. 2005;50(4):245-63.

31. Alberti KG, Zimmet PZ. Definition, diagnosis and classification of diabetes mellitus and its complications. Part 1: diagnosis and classification of diabetes mellitus provisional report of a WHO consultation. Diabet Med. 1998;15(7):539-53.

32. Eze IC, Schaffner E, Foraster M, Imboden M, von Eckardstein A, Gerbase MW, et al. Long-Term Exposure to Ambient Air Pollution and Metabolic Syndrome in Adults. PLoS One. 2015;10(6):e0130337.

33. Liu LJ, Curjuric I, Keidel D, Heldstab J, Kunzli N, Bayer-Oglesby L, et al. Characterization of source-specific air pollution exposure for a large population-based Swiss cohort (SAPALDIA). Environ Health Perspect. 2007;115(11):1638-45.

34. Swiss Agency for the Environment Forests and Landscape. Modelling of PM10 and PM2.5 ambient concentrations in Switzerland 2000 and 2010. Environ Doc 2003;(Nr. 169). 
35. Imboden M, Nieters A, Bircher AJ, Brutsche M, Becker N, Wjst M, et al. Cytokine gene polymorphisms and atopic disease in two European cohorts. (ECRHS-Basel and SAPALDIA). Clin Mol Allerg. 2006;4:9.

36. Purcell S, Neale B, Todd-Brown K, Thomas L, Ferreira MA, Bender D, et al. PLINK: a tool set for whole-genome association and population-based linkage analyses. Am J Hum Genet. 2007:81(3):559-75.

37. Panczak R, Galobardes B, Voorpostel M, Spoerri A, Zwahlen M, Egger M. A Swiss neighbourhood index of socioeconomic position: development and association with mortality. J Epidemiol Community Health. 2012;66(12):1129-36.

38. Hamid YH, Rose CS, Urhammer SA, Glumer C, Nolsoe R, Kristiansen OP, et al. Variations of the interleukin-6 promoter are associated with features of the metabolic syndrome in Caucasian Danes. Diabetologia. 2005;48(2):251-60.

39. Aguilera I, Eeftens M, Meier R, Ducret-Stich RE, Schindler C, Ineichen A, et al. Land use regression models for crustal and traffic-related PM2.5 constituents in four areas of the SAPALDIA study. Environ Res. 2015;140:377-84.

40. Zanobetti A, Baccarelli A, Schwartz J. Gene-air pollution interaction and cardiovascular disease: a review. Prog Cardiovasc Dis. 2011;53(5):344-52.

41. Adam M, Imboden M, Boes E, Schaffner E, Kunzli N, Phuleria HC, et al. Modifying effect of a common polymorphism in the interleukin-6 promoter on the relationship between long-term exposure to traffic-related particulate matter and heart rate variability. PLoS One. 2014;9(8):e104978.

42. Minelli C, Wei I, Sagoo G, Jarvis D, Shaheen S, Burney P. Interactive effects of antioxidant genes and air pollution on respiratory function and airway disease: a HuGE review. Am J Epidemiol. 2011;173(6):603-20.

43. Ljungman P, Bellander T, Schneider A, Breitner S, Forastiere F, Hampel R, et al. Modification of the interleukin- 6 response to air pollution by interleukin- 6 and fibrinogen polymorphisms. Environ Health Perspect. 2009;117(9):1373-9.

44. Vogel CF, Sciullo E, Wong P, Kuzmicky P, Kado N, Matsumura F. Induction of proinflammatory cytokines and C-reactive protein in human macrophage cell line U937 exposed to air pollution particulates. Environ Health Perspect. 2005:113(11):1536-41.

45. Watterson TL, Sorensen J, Martin R, Coulombe Jr RA. Effects of PM2.5 collected from Cache Valley Utah on genes associated with the inflammatory response in human lung cells. J Toxicol Environ Health. 2007; 70(20):1731-44.

46. Bind MA, Lepeule J, Zanobetti A, Gasparrini A, Baccarelli A, Coull BA, et al. Air pollution and gene-specific methylation in the Normative Aging Study: association, effect modification, and mediation analysis. Epigenetics. 2014;9(3):448-58.

47. Ishida K, Kobayashi T, Ito S, Komatsu Y, Yokoyama T, Okada M, et al. Interleukin-6 gene promoter methylation in rheumatoid arthritis and chronic periodontitis. J Periodontol. 2012;83(7):917-25.

48. Aumueller E, Remely M, Baeck H, Hippe B, Brath H, Haslberger AG Interleukin-6 CpG Methylation and Body Weight Correlate Differently in Type 2 Diabetes Patients Compared to Obese and Lean Controls. J Nutrigenet Nutrigenomics. 2015;8(1):26-35.

49. Na YK, Hong HS, Lee WK, Kim YH, Kim DS. Increased methylation of interleukin 6 gene is associated with obesity in Korean women. Mol Cells. 2015;38(5):452-6.

50. Gilbert ER, Liu D. Epigenetics: the missing link to understanding beta-cell dysfunction in the pathogenesis of type 2 diabetes. Epigenetics. 2012:7(8):841-52.

51. Ling C, Groop L. Epigenetics: a molecular link between environmental factors and type 2 diabetes. Diabetes. 2009;58(12):2718-25.

52. Ziegler A, Van Steen K, Wellek S. Investigating Hardy-Weinberg equilibrium in case-control or cohort studies or meta-analysis. Breast Cancer Res Treat. 2011:128(1):197-201.

53. Hosking L, Lumsden S, Lewis K, Yeo A, McCarthy L, Bansal A, et al. Detection of genotyping errors by Hardy-Weinberg equilibrium testing. Eur J Hum Genet. 2004;12(5):395-9.

\section{Submit your next manuscript to BioMed Central and we will help you at every step:}

- We accept pre-submission inquiries

- Our selector tool helps you to find the most relevant journal

- We provide round the clock customer support

- Convenient online submission

- Thorough peer review

- Inclusion in PubMed and all major indexing services

- Maximum visibility for your research

Submit your manuscript at www.biomedcentral.com/submit

) Biomed Central 